\title{
Development of Deflection Prediction Model for Concrete Block Pavement Considering the Block Shapes and Construction Patterns
}

\author{
Wuguang Lin, ${ }^{1}$ Yoon-ho Cho, ${ }^{2}$ and In Tai Kim ${ }^{3}$ \\ ${ }^{1}$ College of Transport \& Communications, Shanghai Maritime University, 1550 Haigang Avenue, Shanghai 201306, China \\ ${ }^{2}$ Department of Civil and Environmental Engineering, Chung-Ang University, 84 Heukseok-Ro, Dongjak-Gu, \\ Seoul 06974, Republic of Korea \\ ${ }^{3}$ Department of Transportation Engineering, Myongii University, San 38-2 Nam-dong, Yongin-si, \\ Gyeonggi-do 449-728, Republic of Korea
}

Correspondence should be addressed to In Tai Kim; kit1998@mju.ac.kr

Received 28 December 2015; Revised 12 April 2016; Accepted 19 April 2016

Academic Editor: Peter Majewski

Copyright (C) 2016 Wuguang Lin et al. This is an open access article distributed under the Creative Commons Attribution License, which permits unrestricted use, distribution, and reproduction in any medium, provided the original work is properly cited.

\begin{abstract}
Concrete block pavement (CBP) is distinct from typical concrete or asphalt pavements. It is built by using individual blocks with unique construction patterns forming a discrete surface layer to bear traffic loadings. The surface structure of CBP varies depending on the block shapes and construction patterns, so it is hard to apply a general equivalent elastic modulus estimation method to define the surface structural strength. In this study, FEM analysis and dynamic loading test were carried out to develop a deflection prediction model for CBP considering the block shapes and construction patterns. Based on the analysis results, it was found that block shapes did not have much effect on load distribution, whereas construction patterns did. By applying the deflection prediction model to the rutting model for CBP proposed by Sun, the herringbone bond pattern showed the best performance comparing with stretcher bond or basket weave bond pattern. As the load repetition increased to 1.2 million, the rutting depth of CBP constructed by herringbone bond pattern was $2 \mathrm{~mm}$ smaller than those constructed by the other two patterns.
\end{abstract}

\section{Introduction}

Concrete block pavement (CBP) has been widely used in sidewalks, motorways, and ports because of its aesthetic features and easy maintenance. Unlike continuous concrete pavement or asphalt pavement, CBP can bear traffic loadings with individual blocks constructed in a uniform pattern. The blocks are connected in a continuous structure with joint sand to minimize the rotation and movement of blocks for structural stability. Therefore, CBP should be viewed as a single system in which all components, the surface layer, bedding sand under the joint sand, and underlying layers are taken into account, rather than considering only the blocks as the layer carrying the applied load or providing a wearing layer or roughness [1].

The load bearing capacity of the CBP increases mainly because of shear force at the joints and compressive force caused by dilatancy of the joint sand. In general, CBP bearing capacity also changes over time compared to the initial service life; with traffic loading increase the pavement strain decreases and load bearing capacity increases due to compaction of the sublayers [2,3]. According to Kuipers [4], the repeated traffic loading causes the rotation of blocks; the construction patterns would affect the performance of CBP when the rotation of blocks at narrow joint intervals reaches its limit. CBP lockup occurs only when a sufficient load is applied over a flexible base. As interlocking efficiency increases, stresses between blocks decrease and are transferred to the substructure. Kuipers [4] proposed that once interlock between the blocks is achieved, the elastic modulus of the joint sand rises around 10 times compared with the initial value. Also the interaction between paving blocks with heavy loading was determined that it could provide increased pavement stiffness and thus increased load dissipation resulting in lower transmitted stress on the subgrade [5]. 
It is difficult to estimate the elastic modulus of the surface layer because of its discrete property. On the basis of findings from previous studies, Shackel [6] recorded the complex elastic modulus of concrete blocks and bedding sand layers measured in FWD test and laboratory test. The elastic modulus varied widely from $500 \mathrm{MPa}$ to $4,000 \mathrm{MPa}$ depending on conditions such as block shape and testing method. CMAA [7] suggested an initial complex elastic modulus of the surface layer (blocks and bedding sand layer) of $350 \mathrm{MPa}(50,750 \mathrm{psi}$ ); the complex elastic modulus would rise to $3,100 \mathrm{MPa}$ $(450,000$ psi) after 10,000 ESALs were applied. Although numerous researchers have presented a wide range of elastic modulus values for the layer of blocks, it seems undesirable to apply only one of them to design CBP structure [8-10].

One of the major structural distresses of a CBP is rutting caused by traffic loading. Rutting of CBPs is the product of horizontal and vertical movements of the blocks. Yasuhisa et al. [11] assessed the conditions of 48 CBPs laid on motorways in service and found that rutting accounted for $40 \%$ of all distresses. Panda and Ghosh [12] proved that the vertical load distribution in pavement structures was not significantly affected by construction patterns. It was found that shape, size, and thickness of the blocks have a significant influence on the behavior of CBP [13]. However, Miura et al. [14] found that pavement performance was influenced more by the block shape and laying pattern than the block thickness by using rutting depth as an indicator. Based on the analysis results of finite-element model, Mampearachchi and Gunarathna [15] pointed that the performance of CBP was found to be affected more by the construction pattern. Then the viewpoint was demonstrated by the deflection basins data measured in the field test [16]. Variation of deflection among different laying patterns was significantly high compared with deflection variations of block shapes. The herringbone bond had the lowest and the stack bond showed the largest deflection. Sun [17] developed a rutting prediction model based on a deflection by considering factors such as traffic load, accumulated traffic volume, resilient deflection of pavement, and block thickness. Several prediction models presented in other studies also did not consider the block shapes and construction patterns $[18,19]$.

In this study, to develop a deflection prediction model for CBP considering the block shapes and construction patterns, a FEM analysis and a dynamic loading test were performed to analyze load-deflection behavior. By using multiregression analysis, a load distribution model based on the deflection was developed and applied to the rutting model proposed by Sun [17]. Then the calculated rut depth was compared with the rutting results measured from Accelerated Pavement Testing (APT).

\section{Rutting Prediction Model}

Rutting of CBP mainly happens when using a granular aggregate base, and it is divided into permanent deformation at the base course and at the subgrade. Rutting is caused by repeated loading and is related to permanent deformation which accumulated in additional compaction of bedding sand at an early stage of service and continued traffic loads at the aggregate base, subbase, and subgrade. If a pavement's substructure (aggregate base, subbase, and subgrade) is relatively weak, shear stress at the joints from a concentrated load exceeds the shear strength at the interlock of the filling sand and blocks, which leads to rut. Rutting at the sublayers deteriorates the performance of the pavement structure and causes poor drainage and roughness. In general, rut depth is a major design standard for CBPs using an aggregate base [17, 20, 21]. Houben et al. [18] presented the rut depth prediction model by taking traffic volume into consideration in the following equation:

$$
\mathrm{RD}=a_{p} \cdot N^{b_{p}}
$$

where RD is rut depth ( $\mathrm{mm}), N$ is the number of load repetitions, and $a_{p}, b_{p}$ are model constants.

Huurman and Boomsma [19] defined rut depth occurring at the CBP through strain at the sand layers and the aggregate base. This empirical model mainly reflects the characteristics of materials in the environment condition of Netherlands, as shown in

$$
\begin{aligned}
\varepsilon_{\text {perm at sand layer }}= & A\left(\frac{N}{1000}\right)^{B} \\
\varepsilon_{\text {perm at aggregate layer }}= & A\left(\frac{N}{1000}\right)^{B} \\
& +C\left(\exp \left(D \frac{N}{1000}\right)-1\right),
\end{aligned}
$$

where $N$ is the number of load repetitions and $A, B, C$, and $D$ are model constants.

It is difficult to accurately estimate the stresses at sublayers of CBP due to the discrete property of the surface layer. Therefore Sun [17] presented a rutting prediction model of CBP by considering factors such as the magnitude of loads, the bearing capacity of structure (resilient deflection), the thickness of block layer, and the number of load repetitions, while the rut depth is relative to both the accumulation of permanent deformation and the lateral distribution of vehicle loads. Based on the regression analysis of test results, the following equation is used for the estimation of the rut depth:

$$
\begin{aligned}
\mathrm{RD}= & 961 C \cdot D_{0} \cdot p_{0}^{-0.16} \cdot r_{0}^{-2.21} \cdot e^{\left(-0.24 D_{0}-0.11 h\right)} \\
& \cdot N^{0.265}
\end{aligned}
$$

where RD is rut depth ( $\mathrm{mm}), D_{0}$ is resilient deflection $(\mathrm{mm})$, $p_{0}$ is load pressure $(\mathrm{MPa}), r_{0}$ is radius of loaded areas $(\mathrm{cm}), h$ is thickness of block (cm), $N$ is number of load repetitions, and $C$ is wheel configuration coefficient; $C=1$ for single wheel and $C=1.17,1.25$, and 1.34 corresponding to $h=8,10$, and $12 \mathrm{~cm}$ for dual wheels.

The rutting model of Huurman and Boomsma [19] is an empirical model reflecting the properties of materials suited for Netherlands. However, Sun's model can predict rutting by calculating the deflection of the pavement structure under diverse conditions for incorporation at the design stage. The allowable design rut depth for CBP with a flexible base varies depending on the location of construction and its function. 


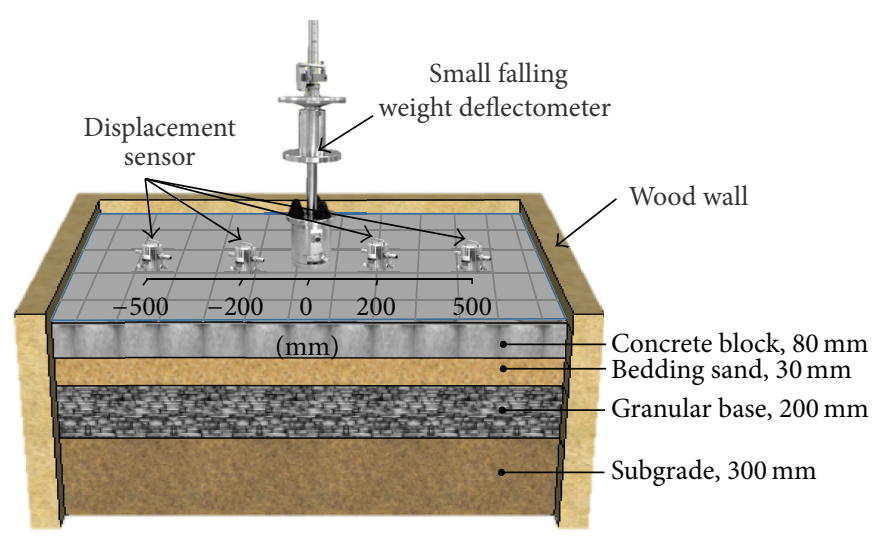

FIgURE 1: Specification of dynamic laboratory loading test.

Allowable rut depth for ports in China is $30 \mathrm{~mm}$ [17] and that for motorways is $15 \mathrm{~mm}$ [20] in Netherlands and $35 \mathrm{~mm}$ [21] in Japan.

\section{Methodology to Develop Deflection Prediction Model}

3.1. Laboratory Loading Test. As shown in Figure 1, the loading test was conducted in a $1,500 \mathrm{~mm} \times 1,500 \mathrm{~mm} \times 700 \mathrm{~mm}$ test pit. In this test, a section with $80 \mathrm{~mm}$ blocks for the surface layer, $30 \mathrm{~mm}$ for bedding sand, $200 \mathrm{~mm}$ aggregate layer, and $300 \mathrm{~mm}$ subgrade was used. In order to avoid the loss of bedding sand, a geotextile was placed between the base and bedding sand. Three construction patterns considered in most of the CBP design guide (ASCE 2015) [7, 21] were assessed: stretcher, basket weave, and herringbone bond, which were the same test variables in Mampearachchi and Senadeera's study [16]. The blocks used in this test were $200 \mathrm{~mm} \times 100 \mathrm{~mm} \times 80 \mathrm{~mm}$ rectangular blocks. Flexural strength and dynamic elastic modulus tests were in accordance with ASTM C 78 and ASTM C 215 [22, 23] and were found to be $4.77 \mathrm{MPa}$ and $12.09 \mathrm{GPa}$, respectively. The bulk density of the blocks was $2.24 \mathrm{~kg} / \mathrm{mm}^{3}$. The particle size analysis was performed for the joint sand, bedding sand, and permeable base material [24]. Figure 2 indicates the results of the passing ratio analysis of the base material, bedding sand, and joint sand; the passing ratios of the bedding sand and joint sand met ASTM C 33 and ASTM C 144, respectively, and the base material was uniformly distributed in aggregate sizes ranging from $40 \mathrm{~mm}$ to $2 \mathrm{~mm}[25,26]$.

A light falling weight deflectometer (LFWD) model KFD100A produced by Tokyo Sokki Kenkyujo Co., Ltd., was used to investigate the load-deflection behavior. A $9000 \mathrm{~N}$ load was applied on a $150 \mathrm{~mm}$ radius plate in the center of the test pit. In order to identify the scope of the deflection caused by loading, deflection sensors were installed which can measure deflection of up to $1 \mathrm{~mm}$ at the loading point and at spots $200 \mathrm{~mm}$ and $500 \mathrm{~mm}$ away to right and left from the loading point.

3.2. Structural Analysis Model. A three-dimensional (3D) finite-element analysis of the CBP using ABAQUS 6.10 [27]

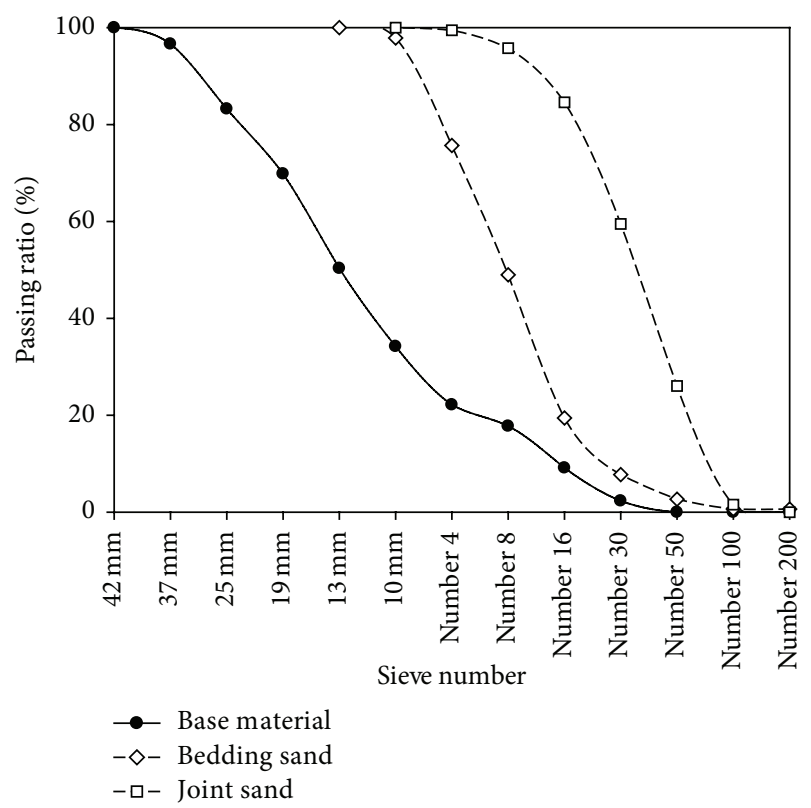

FIGURE 2: Passing ratios of sand and base material.

was performed with C3D8R as the element used in the analysis. Figure 3 shows the element configuration and system for the structural analysis considering three layers, which were the block surface layer, bedding sand layer, and base layer in an area of $1.5 \mathrm{~m} \times 1.5 \mathrm{~m}$. The blocks were connected with a joint sand element. The joint width was fixed to $3 \mathrm{~mm}$ and the sides of the test pit were in roller boundary condition to create the same condition as in the loading test. All of the elements were modeled as solid-deformable bodies having homogeneous and elastic property. The model was subjected to a linear static loading analysis. The subgrade is defined as a set of spring elements beneath the base layer to simulate the subgrade reaction by using the spring coefficient $k$. The equidistant meshes were used for different analytical factors. The blocks, joint sand element, and layers of the pavement were fully bonded. The loading on the concrete blocks was 


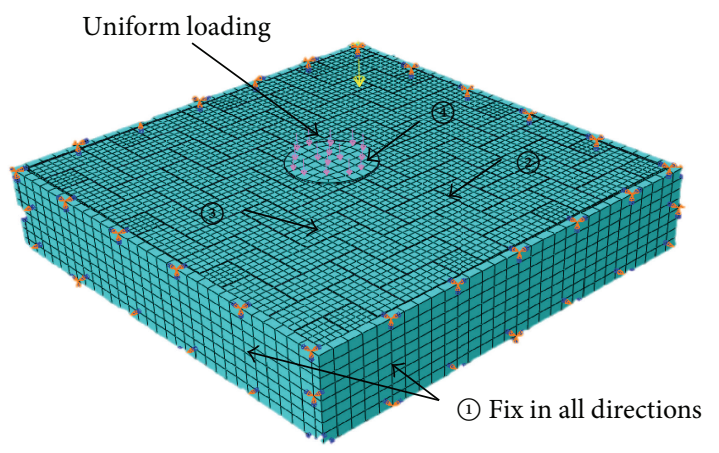

(1) $1.5 \times 1.5 \times 0.61 \mathrm{~m}$ plate (3) Rigid block pavers (2) Joint sand element $\quad$ (4) $300 \mathrm{~mm}$ diameter rubber pads

FIgURE 3: 3D structural analysis model.

applied uniformly on the circular steel plates with a diameter of $300 \mathrm{~mm}$.

Input values from prior researches were used to select the block size, soil support condition, block thickness, construction pattern, loading scale, and contact area as factors affecting the vertical behavior of CBPs [17]. Yaginuma et al. [28] generalized block shapes as a shape factor (ratio of total side area to top area, SF) to determine the proper sizes for a block that can be used for roads and argued that a larger SF leads to higher load transfer efficiency between blocks. The $\mathrm{SF}$ concept was designed to simulate block shapes. Five levels of SF used in the analysis were 2.3 to 2.7 at intervals of 0.1 , calculated according to blocks in wide use in Korea. The ratio of length to width of the blocks was fixed at a $2: 1$.

Three construction patterns were simulated as the same with lab test. The elastic modulus of the base was assessed for four levels which were $100 \mathrm{MPa}, 300 \mathrm{MPa}, 500 \mathrm{MPa}$, and $740 \mathrm{MPa}$. Further, subgrade reaction was considered at three levels which were high ( $300 \mathrm{pci})$, medium (200 pci), and low (100 pci). Three different block thicknesses were used in the model, which were $60 \mathrm{~mm}, 80 \mathrm{~mm}$, and $100 \mathrm{~mm}$ blocks. The base was built from $150 \mathrm{~mm}$ to $300 \mathrm{~mm}$ at intervals of $50 \mathrm{~mm}$. Since previous studies had reported that the elastic modulus of the blocks had an insignificant effect on pavement performance, this was not considered in the analysis [29].

Input data for the 3D FEM analysis include load, the material properties and thickness of the pavement layer, and the soil support value. Table 1 summarized the properties of the materials employed for the structural analysis. The elastic modulus of the block was evaluated by the laboratory test; therefore the elastic modulus of the joint and bedding sands was used as presented in previous studies [15].

\section{Load-Deflection Behavior}

To evaluate the load-deflection behavior, 10 times of the test loads were dropped for each experimental variable. Table 2 summarized the average, standard deviation, and normalized value calculated by load-deflection data obtained in dynamic loading test. The herringbone bond pattern had the lowest
TABLE 1: Properties of materials used for the structural analysis.

\begin{tabular}{lccc}
\hline & $\begin{array}{c}\text { Elastic modulus } \\
(\mathrm{MPa})\end{array}$ & $\begin{array}{c}\text { Density } \\
\left(\mathrm{kg} / \mathrm{mm}^{3}\right)\end{array}$ & Poisson's ratio \\
\hline Block & 12090 & $2.435 e-06$ & 0.2 \\
Joint sand & 10 & $1.732 e-06$ & 0.26 \\
Bedding sand & 10 & $1.732 e-06$ & 0.26 \\
Granular base & 240 & $2.4 e-06$ & 0.3 \\
\hline
\end{tabular}

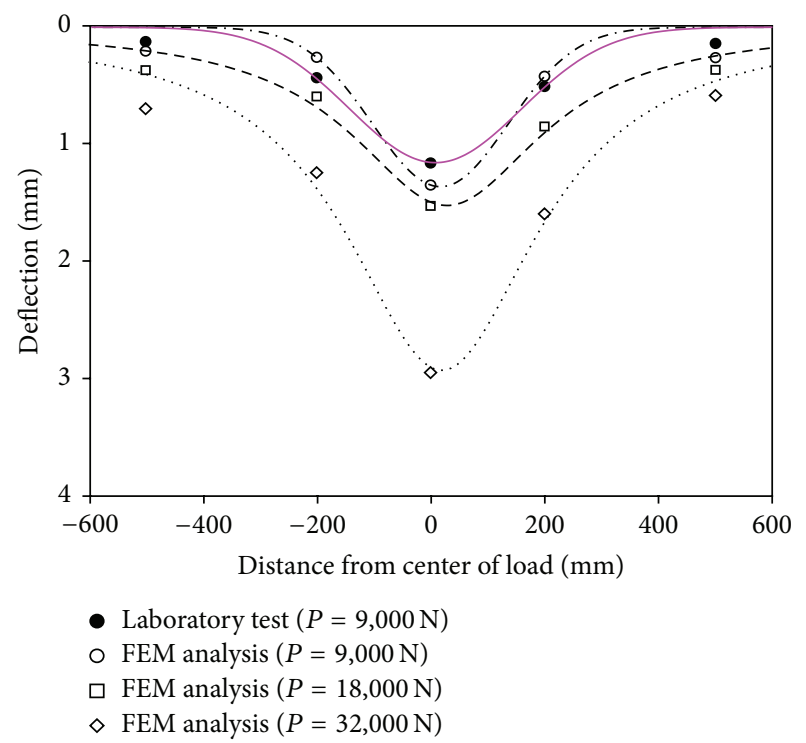

FIGURE 4: Comparison of deflection from the analysis and test (stretcher).

and the stretcher bond showed the largest in maximum deflection. Figures 4-6 show the comparison results of deflection curves from FEM analysis and lab test for each construction pattern. Both the test results and analysis results in a $9,000 \mathrm{~N}$ load condition appeared similar in all construction patterns, but deflection basin differed among construction patterns. By considering maximum deflection, the stretcher bond had an estimated $1.2 \mathrm{~mm}$ of deflection, and the value fell by $25 \%$ to $0.9 \mathrm{~mm}$ in the herringbone bond with a noticeably different deflection curvature. The curvature is proportional to stress; it was presumed that the stress levels are from high to low, followed by stretcher, basket weave, and herringbone. In the FEM analysis, tensile stress on the base ranged from 60 to $100 \mathrm{kPa}$ depending on the construction patterns in the condition of a $9,000 \mathrm{~N}$ load with a $300 \mathrm{~mm}$ radius. The heavier load led to a stronger effect on the deflection of the patterns. Because the lab test results and analytical results were matched well, the analytical model was set up to estimate the deflection for the remaining variables such as construction patterns and block shapes.

\section{Multiregression Analysis of Deflection}

Although the deflection obtained from a 3D FEM analysis can be reflected into the design as it is, determining the value 
TABLE 2: Summary of average, standard deviation, and normalized deflection for each pattern.

\begin{tabular}{lccccccc}
\hline & & Load (N) & $D_{0}$ & $D_{1}$ & $D_{2}$ & $D_{3}$ & $D_{4}$ \\
\hline \multirow{3}{*}{ Stretcher bond } & Average & 9146.4 & 1.172 & 0.436 & 0.124 & 0.511 & 0.140 \\
& Standard deviation & 91.6 & 0.023 & 0.061 & 0.014 & 0.045 & 0.021 \\
& Normalized to 9000 N & 9000.0 & 1.153 & 0.429 & 0.122 & 0.503 & 0.138 \\
\hline \multirow{3}{*}{ Basket weave } & Average & 8729.9 & 1.026 & 0.487 & 0.103 & 0.573 & 0.154 \\
& Standard deviation & 78.8 & 0.034 & 0.018 & 0.016 & 0.044 & 0.032 \\
& Normalized to 9000 N & 9000.0 & 1.058 & 0.502 & 0.106 & 0.591 & 0.159 \\
\hline \multirow{3}{*}{ Herringbone bon } & Average & 9319.3 & 0.918 & 0.567 & 0.135 & 0.437 & 0.144 \\
& Standard deviation & 64.4 & 0.049 & 0.051 & 0.008 & 0.042 & 0.025 \\
& Normalized to 9000 N & 9000.0 & 0.886 & 0.547 & & 0.131 & 0.422 \\
\hline
\end{tabular}

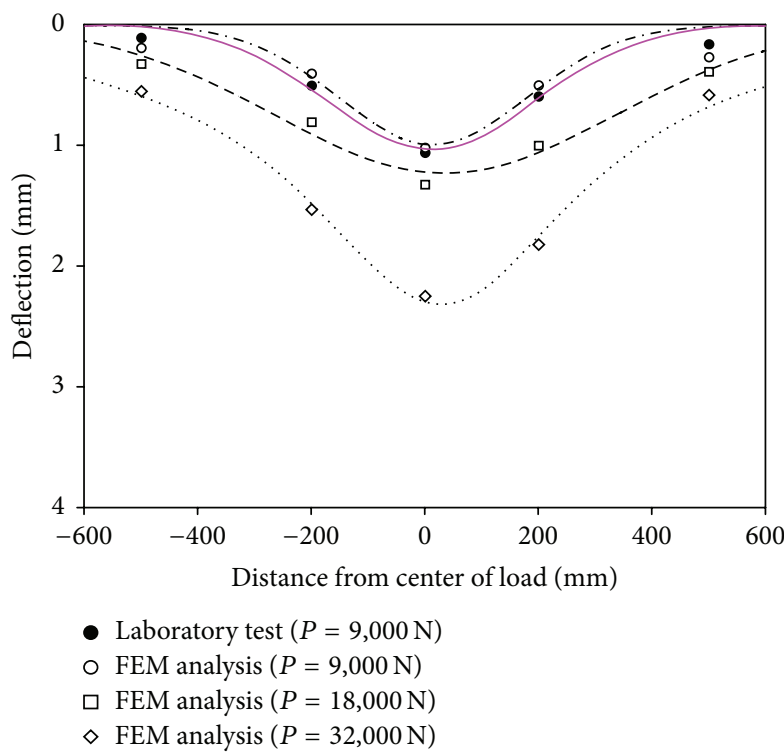

Figure 5: Comparison of deflection from the analysis and test (basket weave).

under various conditions and conducting a regression analysis reduces design time, which is a recent trend in pavement design [30]. In the load distribution model for CBP, the maximum deflection obtained from the analysis was considered as resilient deflection and a dependent variable in a regression analysis using PASW Statistics 18. Among the independent variables were shape factor $(\mathrm{SF})$, contact area $\left(R_{0}\right)$, applied load $\left(P_{0}\right)$, subgrade reaction coefficient $k$, pattern $\left(p_{h}\right)$, block thickness $\left(h_{1}\right)$, base thickness $\left(h_{2}\right)$, and elastic modulus of the base $\left(E_{b}\right)$. Since construction pattern is on a nominal scale that is difficult to use in a regression analysis, a binary variable was used in values " 0 " without applying a herringbone pattern and "1" with applying a herringbone pattern. A total of 200 FEM analyses were performed with the variables range of SF of 2.3 to 2.7 , traffic loading of $0.125 \mathrm{MPa}$ to $0.6 \mathrm{MPa}$, base thickness of 20 to $30 \mathrm{~cm}$, and block thickness of 6 to $10 \mathrm{~cm}$. The estimation method for the multiregression equation was using a simultaneous input to examine the influence of specific independent variables with the other independent variables controlled.

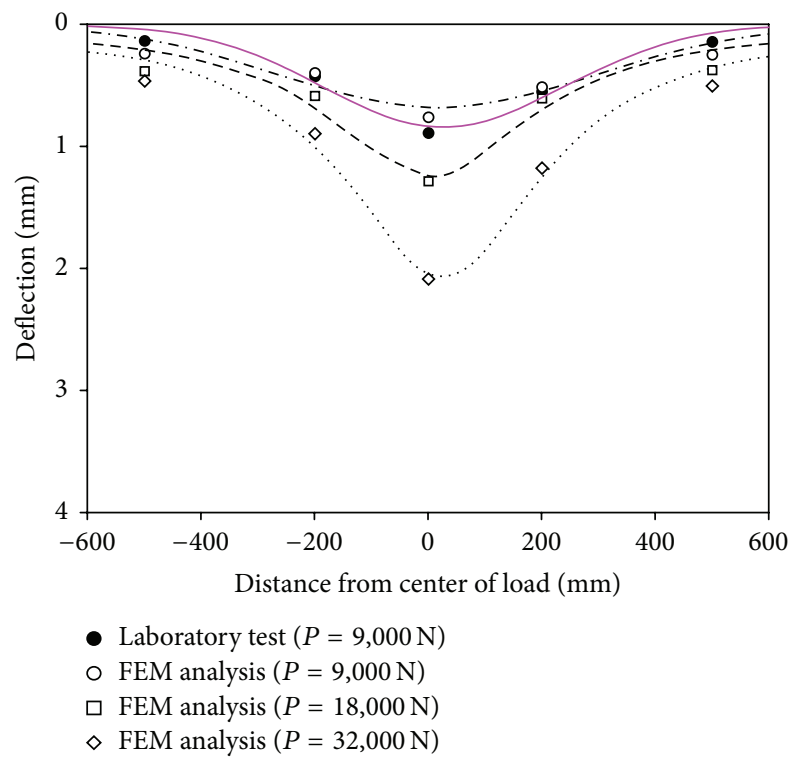

FIGURE 6: Comparison of deflection from the analysis and test (herringbone).

The results of the multiregression analysis, excluding variables rejected by significant probability, are summarized in Table 3. This multiregression analysis model can explain $91.5 \%$ of the deflection caused by the independent variables. The Durbin-Watson value verifies the satisfaction of the independence of error. In Table 4, which shows the coefficients from the multiregression analysis on deflection prediction, the significance probability (sig.) for all of the dependent variables except pattern 3 is less than 0.05 , which statistically fits the regression model. Although the value is bigger than 0.05 , the significance probability (sig.) of pattern 3 , which is 0.07 , also fits the regression model.

The equation to calculate resilient deflection considering the various block shapes, thicknesses, and patterns is given as

$$
\begin{aligned}
D_{0}= & 3.847-0.201 \mathrm{SF}-0.002 R_{0}+5.356 e^{-5} P_{0} \\
& -0.073 p_{h}-0.02 h_{1}-0.005 h_{2}-0.001 E_{b},
\end{aligned}
$$

where $D_{0}$ is maximum deflection ( $\mathrm{mm}$ ), SF is shape factor, $R_{0}$ is diameter of grounding area $(\mathrm{mm}), P_{0}$ is applied load $(\mathrm{N})$, 
TABLE 3: Summary of multiregression analysis model for deflection.

\begin{tabular}{|c|c|c|c|c|c|}
\hline \multicolumn{6}{|c|}{ Model summary ${ }^{\mathrm{b}}$} \\
\hline Model & $R$ & $R$ square & Adjusted $R$ square & Std. error of the estimate & Durbin-Watson \\
\hline 1 & $0.956^{\mathrm{a}}$ & 0.915 & 0.911 & 0.22717 & 1.815 \\
\hline
\end{tabular}

TABLE 4: Coefficients of multiregression analysis for deflection.

\begin{tabular}{|c|c|c|c|c|c|c|c|c|}
\hline \multirow{3}{*}{ Model } & & & \multirow{3}{*}{$\begin{array}{c}\text { Coefficients }^{\mathrm{a}} \\
\text { Standardized coefficients } \\
\text { Beta }\end{array}$} & \multirow{3}{*}{$t$} & \multirow{3}{*}{ Sig. } & \multirow{2}{*}{\multicolumn{3}{|c|}{ Correlations }} \\
\hline & \multicolumn{2}{|c|}{ Unstandardized coefficients } & & & & & & \\
\hline & $B$ & Std. error & & & & Zero-order & Partial & Part \\
\hline (Constant) & 3.847 & 0.406 & & 9.475 & 0.000 & & & \\
\hline Shape factor & -0.201 & 0.088 & -0.048 & -2.287 & 0.023 & 0.077 & 0.163 & 0.048 \\
\hline$R_{0}$ & -0.002 & 0.000 & -0.218 & -8.737 & 0.000 & 0.335 & -0.533 & -0.184 \\
\hline$P_{0}$ & $5.356 E-5$ & 0.000 & 0.928 & 35.684 & 0.000 & 0.899 & 0.932 & 0.753 \\
\hline Pattern 3 & -0.073 & 0.041 & -0.040 & -1.797 & 0.074 & -0.319 & -0.129 & -0.038 \\
\hline Thickness 1 & -0.020 & 0.003 & -0.128 & -6.087 & 0.000 & -0.128 & -0.402 & -0.128 \\
\hline Thickness 2 & -0.005 & 0.001 & -0.113 & -4.973 & 0.000 & 0.219 & -0.338 & -0.105 \\
\hline$E_{b}$ & -0.001 & 0.000 & -0.283 & -11.811 & 0.000 & -0.513 & -0.649 & -0.249 \\
\hline
\end{tabular}

${ }^{\mathrm{a}}$ Dependent variable: $D_{0}$.

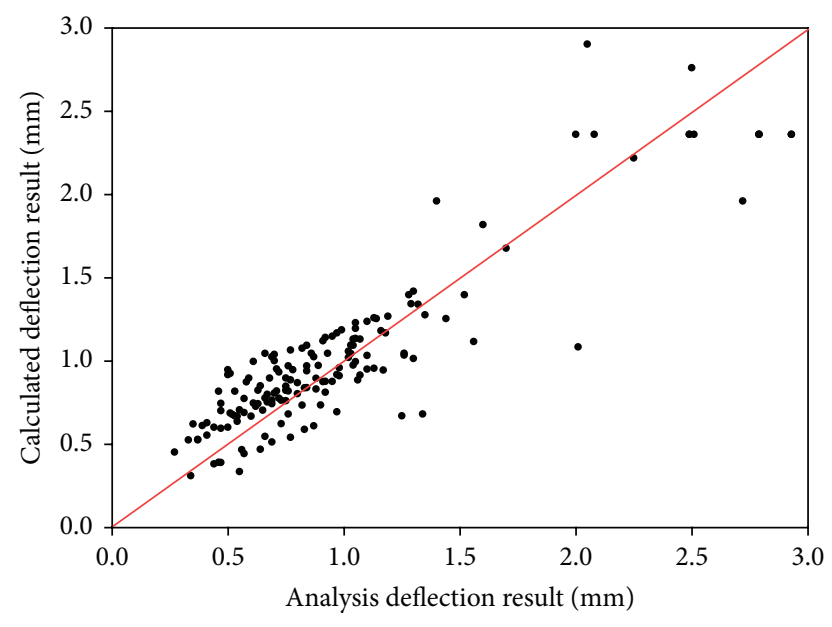

FIGURE 7: Comparison of analysis and calculated deflection results.

$h_{1}$ is block thickness (mm), $h_{2}$ is base thickness (mm), $p_{h}$ : $p_{h}=1$ for herringbone pattern and $p_{h}=0$ for nonherringbone pattern, and $E_{b}$ is elastic modulus of base ( $\left.\mathrm{MPa}\right)$.

Deflection as a dependent variable increases or declines with $B$ value as the values of the independent variables change. Block shapes and construction patterns influence changes in the value of the deflection. If load $P_{0}$ increases, deflection increase by $5.356 E-5$, and as the value of additional independent variables grows, deflection drops. Figure 7 compares the deflection from the analysis and the value calculated in the model. As deflection grows, the model appears unstable, which can be utilized in designing.

\section{Application of Rutting Prediction Model}

The developed deflection prediction model was implemented at the CBP rutting model suggested by Sun [17] in (3). APT results were used to verify the validity of the rutting model of Sun [17]. The specific methodology for the APT and findings are presented in Lin et al. [31].

The test sections were consistent with an $80 \mathrm{~mm}$ surface layer laying herringbone pattern, a $30 \mathrm{~mm}$ sand layer, and $200 \mathrm{~mm} / 300 \mathrm{~mm}$ thickness base layers. Resilient deflection was measured with FWD, which was applied to the rut depth prediction model to verify the validity of the developed equation. With a load condition of $40 \mathrm{kN}, 0.871 \mathrm{~mm}$ and $0.736 \mathrm{~mm}$ of deflection occurred in cross sections with a base thickness of $200 \mathrm{~mm}$ and $300 \mathrm{~mm}$, respectively. The rut depth was evaluated in five phases depending on the number of load repetitions for each pavement in the transverse direction. APT was operated at 100,000 cycles, representing 1.08 million total ESALs. The rut depth is shown in Figures 8 and 9. Under the total load of 1,081,000 ESALs, the rutting depths of block pavement with a granular aggregate base of $30 \mathrm{~cm}$ and $20 \mathrm{~cm}$ were $21 \mathrm{~mm}$ and $25 \mathrm{~mm}$, respectively.

The accumulated rutting measured in the APT and the rut depths calculated in Sun's model are shown in Figure 10, with a similar trend of rutting caused by growing traffic load; the rut depth calculated using the developed deflection estimation model was the largest, and the result obtained from applying the FWD deflection data to Sun's model was the smallest. The results have shown that the prediction model was reasonable from a more conservative perspective, and the error in terms of methodology was small as $5 \mathrm{~mm}$ of rutting in 1,000,000 ESALs. Therefore, the proposed model is adequate to be applied in the design. 


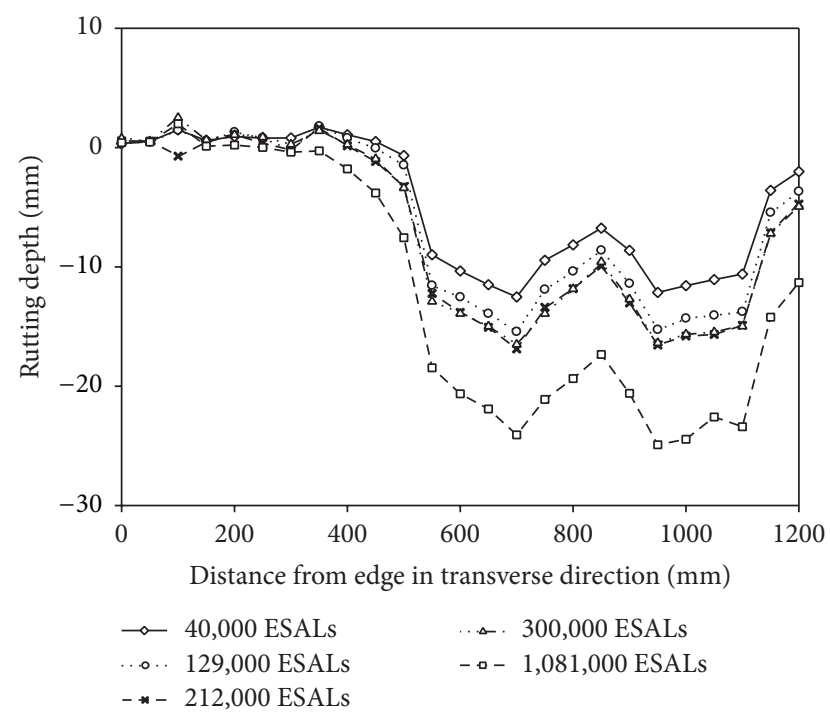

Figure 8: Rutting depth by traffic load (200 mm thick base).

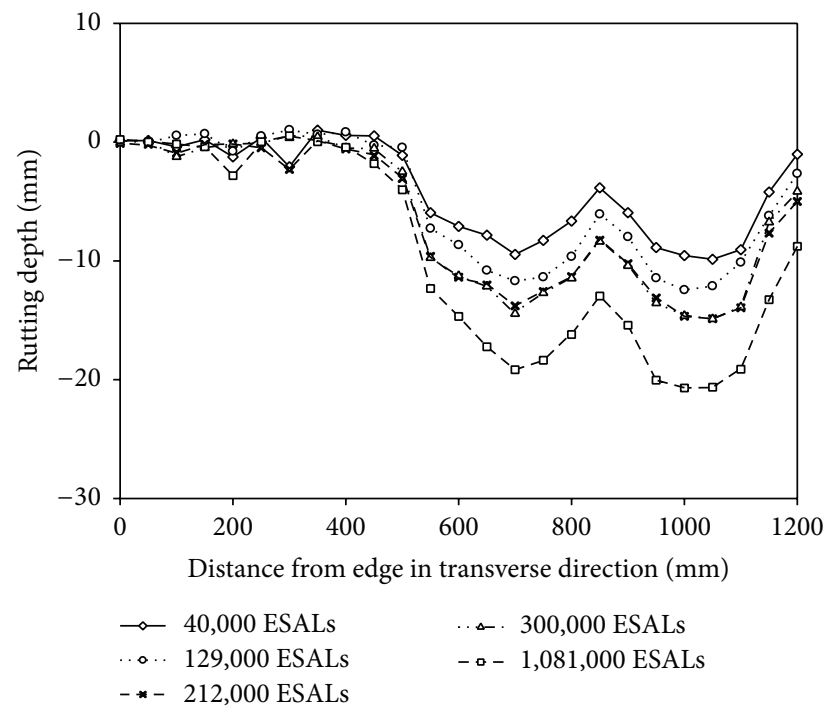

FIGURE 9: Rutting depth by traffic load (300 mm thick base).

To assess rutting by the thickness of the block and base, block shapes, and construction patterns, (4) was applied to Sun's [17] model for sensitivity analysis. Block thicknesses used were $60 \mathrm{~mm}, 80 \mathrm{~mm}$, and $100 \mathrm{~mm}$; base thicknesses were $200 \mathrm{~mm}, 250 \mathrm{~mm}$, and $300 \mathrm{~mm}$; and block shapes of SF were 2.2, 2.4, and 2.6. The contact radius was $150 \mathrm{~mm}$. A $40 \mathrm{kN}$ load was applied to a dual wheel. Figure 11 depicts differences in the rut depth depending on block thickness. During the early age of service, rut depth rose sharply with all variables. Rutting varied largely as the traffic load increased. As block thickness increases from $60 \mathrm{~mm}$ to $100 \mathrm{~mm}$, rut depth dropped by $25 \%$. Laying in a herringbone pattern was set to be relatively lower rut depth up to $2 \mathrm{~mm}$. These findings are similar to those presented by Hiroshi et al. [32].

Figure 12 shows differences in rut depth depending on base thickness with block thickness fixed to $80 \mathrm{~mm}$. As base

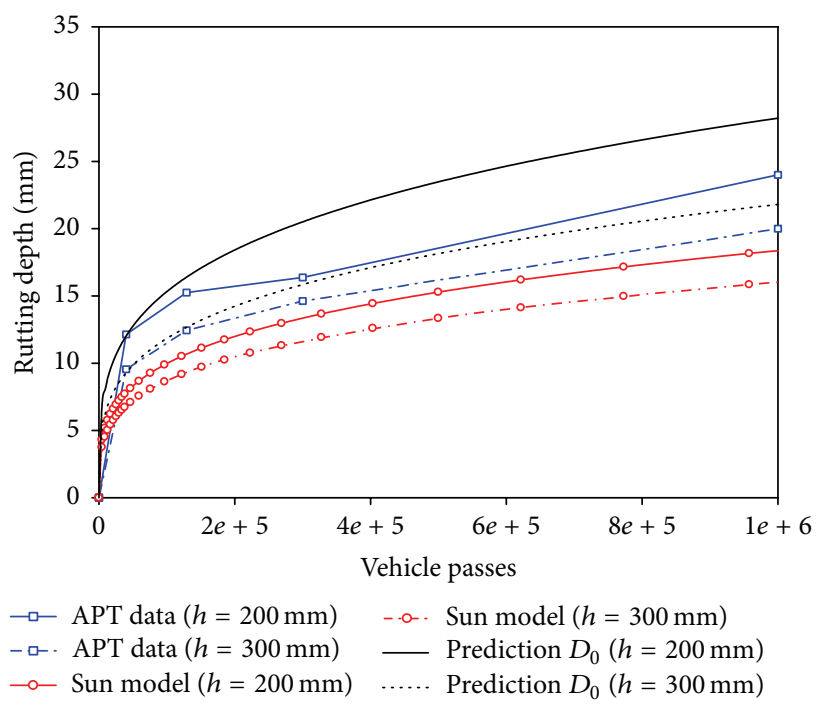

FIgure 10: Difference in rutting depth between the APT data and the model.

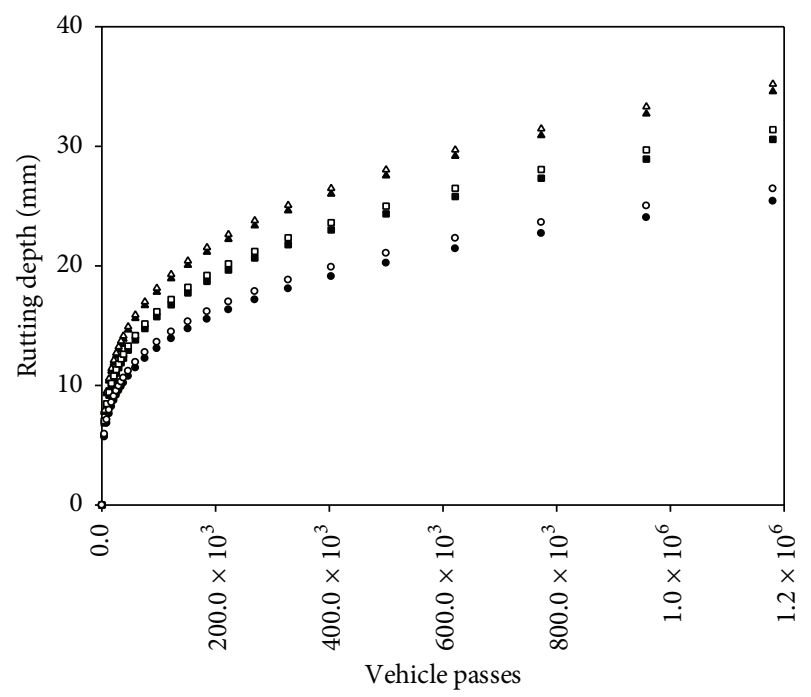

- Herringbone, $h_{1}=60 \mathrm{~mm}$
- Herringbone, $h_{1}=80 \mathrm{~mm}$
- Herringbone, $h_{1}=100 \mathrm{~mm}$
$\Delta$ Nonherringbone, $h_{1}=60 \mathrm{~mm}$
- Nonherringbone, $h_{1}=80 \mathrm{~mm}$
- Nonherringbone, $h_{1}=100 \mathrm{~mm}$

FIGURE 11: Difference in rut depth depending on block thickness.

thickness rose from $200 \mathrm{~mm}$ to $300 \mathrm{~mm}$, rut depth decreased by $22 \%$. Laying blocks in a herringbone pattern decreased rut depth by up to $2 \mathrm{~mm}$, as it did when the block thickness was used as a variable. Increasing the block thickness by $20 \mathrm{~mm}$ or the base thickness from $50 \mathrm{~mm}$ to $100 \mathrm{~mm}$ also resulted in similar performances.

Figure 13 depicts differences in rut depth depending on block shapes (SF) with the block and base thickness fixed to $80 \mathrm{~mm}$ and $200 \mathrm{~mm}$, respectively. As shown in Figure 13, the difference in rut depth depending on block shape was 


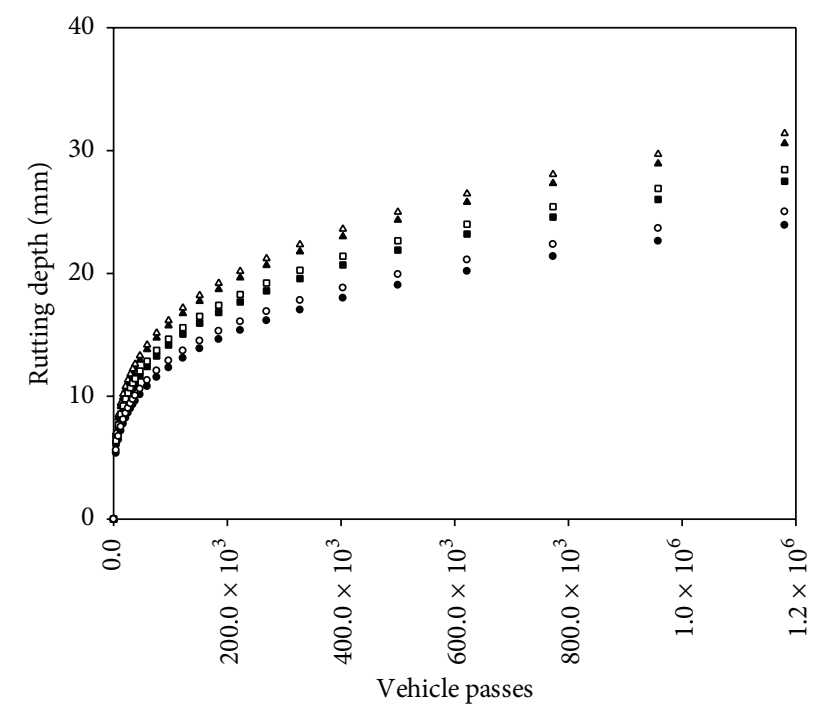

A Herringbone, $h_{2}=200 \mathrm{~mm}$

- Herringbone, $h_{2}=250 \mathrm{~mm}$

- Herringbone, $h_{2}=300 \mathrm{~mm}$

$\triangle$ Nonherringbone, $h_{2}=200 \mathrm{~mm}$

口 Nonherringbone, $h_{2}=250 \mathrm{~mm}$

。 Nonherringbone, $h_{2}=300 \mathrm{~mm}$

FIGURE 12: Difference in rut depth depending on base thickness.

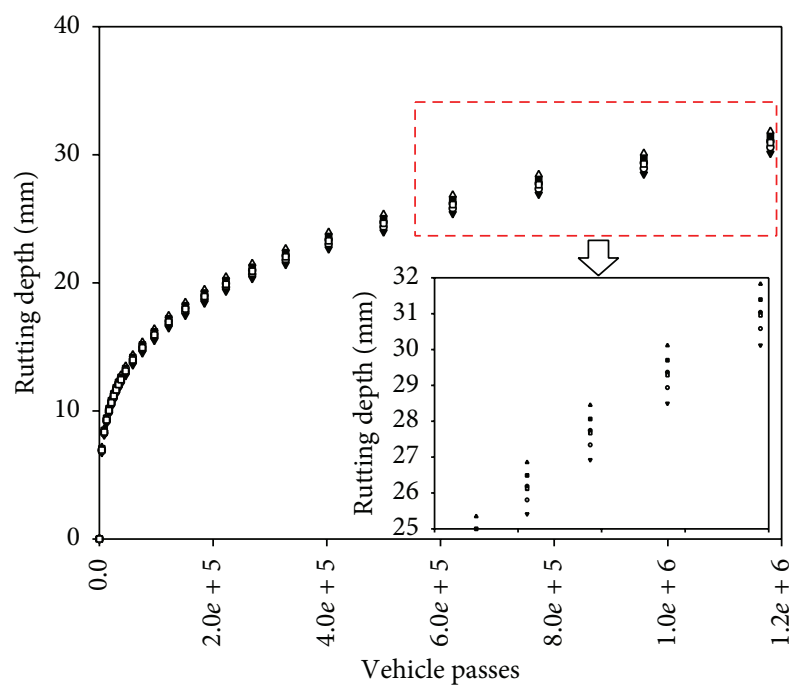

- Herringbone, $\mathrm{SF}=2.2$

- Herringbone, $\mathrm{SF}=2.4$

- Herringbone, $\mathrm{SF}=2.6$

$\triangle$ Nonherringbone, $\mathrm{SF}=2.2$

- Nonherringbone, $\mathrm{SF}=2.4$

- Nonherringbone, $\mathrm{SF}=2.6$

FIgURE 13: Difference in rut depth depending on block shapes.

insignificant; rut depth was found to be affected more by the construction pattern than by block shape. These findings are similar to those from a field test [16]. It is inconclusive, however, that construction pattern is the only determinant in load distribution effect. Because CBP performs as a complex interlocking mechanism of horizontal, vertical, and rotational behaviors, it seems unreasonable to evaluate its performance by separating construction patterns and block shapes too strictly.

\section{Conclusions}

In this study, a resilient deflection prediction model was developed to estimate rutting of CBP. Diverse sets of block shapes and construction patterns were assessed using FEM analysis and dynamic loading test. LFWD was used for the loading test to evaluate correlations between loading and deflection depending on block shape and construction pattern. In order to verify the validity of the test results and develop a deflection prediction model for CBP, 3D FEM modeling simulations were performed using ABAQUS 6.10 [27].

In addition, a resilient deflection estimation model was developed for CBP that considers construction patterns and block shapes via a multiregression analysis. Among the independent variables of the model were contact radius $\left(R_{0}\right)$, load $\left(P_{0}\right)$, block shape and construction pattern, block thickness $\left(h_{1}\right)$, base thickness $\left(h_{2}\right)$, and elastic modulus $\left(E_{b}\right)$. The deflection prediction model for CBP was applied to the existing rutting model and results show that as block thickness increases from $60 \mathrm{~mm}$ to $100 \mathrm{~mm}$, rut depth dropped by $25 \%$ with the load repetition increasing to 1.2 million. By increasing the thickness of base from $200 \mathrm{~mm}$ to $300 \mathrm{~mm}$, rut depth could be reduced by $22 \%$. Increasing the thickness of the surface layer by $20 \mathrm{~mm}$ has similar rutting resistance performances by increasing the base thickness from $50 \mathrm{~mm}$ to $100 \mathrm{~mm}$. It was found out that the block shape did not have significant effects on load distribution, but construction pattern was a relevant parameter. Laying in a herringbone pattern was set to be relatively lower rut depth than the other up to $2 \mathrm{~mm}$.

However, it is inconclusive that construction pattern is the only determinant in load distribution effect. Because CBP performs as a complex interlocking mechanism of horizontal, vertical, and rotational behaviors, it seems unreasonable to evaluate its performance by separating construction patterns and block shapes too strictly.

\section{Competing Interests}

The authors declare that they have no competing interests.

\section{Acknowledgments}

This work was supported by a National Research Foundation of Korea (NRF) grant funded by the Korean Government (MSIP) (no. 2014R1A2A2A01007697).

\section{References}

[1] B. Shackel and D. O. O. Lim, "Mechanism of paver interlock," in Proceedings of the 7th International Conference on Concrete Block Paving (CBP '03), Sun City, South Africa, 2003.

[2] B. Shackel, Design and Construction of Interlocking Concrete Block Pavements, Elsevier Applied Science Publishing, New York, NY, USA, 1990. 
[3] G. R. Rada, P. J. Stephanos, and S. D. Tayabji, Performance of Interlocking Concrete Pavements in North Ametica, Transportation Research Record no. 1388, Washington, DC, USA, 1993.

[4] G. Kuipers, "The effect of concrete block lock-up on pavement performance," in Proceedings of the 4th International Conference on Concrete Block Paving (CBP '92), vol. 1, pp. 51-59, Auckland, New Zealand, February 1992.

[5] M. N. Soutsos, K. Tang, H. A. Khalid, and S. G. Millard, "The effect of construction pattern and unit interlock on the structural behaviour of block pavements," Construction and Building Materials, vol. 25, no. 10, pp. 3832-3840, 2011.

[6] B. Shackel, "The development and application of mechanistic design procedures for concrete block paving," in Proceedings of the 6th International Workshop on Collaborative Business Processes (CBP '00), pp. 13-22, JIPEA World Congress, 2000.

[7] Concrete Masonry Association of Australia, Concrete Segmental Pavements-Design Guide for Residential Accessways and Roads, Concrete Masonry Association of Australia, Sydney, Australia, 1997.

[8] J. Knapton, "The structural design of heavy industrial pavements," Proceedings of the Institution of Civil Engineers, vol. 78, no. 1, part 1, pp. 179-194, 1985.

[9] G. R. Rada, D. R. Simith, J. S. Miller, and M. W. Witczak, "Structural design of interlocking concrete pavement in North America," in Proceedings of the 4th Structural Design of Interlocking Concrete Pavement in North America, vol. 1, pp. 99-116, Auckland, New Zealand, 1992.

[10] D. O. Oldfield, "Webb dock container terminal pavements ten years on," in Proceedings of the 4th International Concrete Block Paving Conference, vol. Vol 2, pp. 209-216, Auckland, New Zealand, 1992.

[11] K. Yasuhisa, Y. Ando, S. Omoto, K. Yaginuma, and K. Toriiminami, "Study on block shifting of interlocking block pavement," in Proceedings of the 8th International Conference on Concrete Block Paving (CBP '06), pp. 447-456, San Francisco, Calif, USA, November 2006.

[12] B. C. Panda and A. K. Ghosh, "Structural behavior of concrete block paving. I: sand in bed and joints," Journal of Transportation Engineering, vol. 128, no. 2, pp. 123-129, 2002.

[13] B. C. Panda and A. K. Ghosh, "Structural behavior of concrete block paving. II: concrete blocks," Journal of Transportation Engineering, vol. 128, no. 2, pp. 130-135, 2002.

[14] Y. Miura, M. Takaura, and T. Tsuda, "Structural design of concrete block pavements by CBR method and its evaluation," in Proceedings of the 2nd International Conference on Concrete Block Paving (CBP '84), pp. 152-157, Delft, The Netherlands, April 1984.

[15] W. K. Mampearachchi and W. P. H. Gunarathna, "Finiteelement model approach to determine support conditions and effective layout for concrete block paving," Journal of Materials in Civil Engineering, vol. 22, no. 11, pp. 1139-1147, 2010.

[16] W. K. Mampearachchi and A. Senadeera, "Determination of the most effective cement concrete block laying pattern and shape for road pavement based on field performance," Journal of Materials in Civil Engineering, vol. 26, no. 2, pp. 226-232, 2014.

[17] L. Sun, "Design theory and method of interlocking concrete block paving for port areas," in Proceedings of the 5th International Conference on Concrete Block Paving (CBP '96), pp. 463472, Tel Aviv, Israel, 1996.

[18] L. J. M. Houben, A. A. A. Molenaar, G. H. A. M. Fuchs, and H. O. Moll, "Analysis and design of concrete block pavements," in Proceedings of the 2nd International Conference on Concrete Block Paving (CBP '84), pp. 86-99, Delft, Netherlands, April 1984.

[19] M. Huurman and W. Boomsma, "Mechanical behaviour of a permeable base and bedding material and the rutting behaviour," in Proceedings of the 8th International Conference on Concrete Block Paving (CBP '06), pp. 61-72, San Francisco, Calif, USA, November 2006.

[20] M. Huurman, L. J. M. Houben, C. W. A. Geense, and J. J. M. Vring, "The upgrade dutch design method for concrete block road pavements," in Proceedings of the 7th International Conference on Concrete Block PAVE AFRICA (CBP '03), Sun City, South Africa, 2003.

[21] Japan Interlocking Block Pavement Engineering Association (JIBPEA), Design and Construction Guidelines for Interlocking Block Pavement, Japan Interlocking Block Pavement Engineering Association (JIBPEA), Tokyo, Japan, 2000 (Japanese).

[22] ASTM International, Standard Test Method for Flexural Strength of Concrete (Using Simple Beam with Third-Point Loading), ASTM International, West Conshohocken, Pa, USA, 2002.

[23] ASTM C 215, Standard Test Method for Fundamental Transverse, Longitudinal, and Torsional Resonant Frequencies of Concrete Specimens, ASTM International, West Conshohocken, Pa, USA, 2008.

[24] ASTM C 136, Standard Test Method for Sieve Analysis of Fine and Coarse Aggregates, ASTM International, West Conshohocken, $\mathrm{Pa}$, USA, 2006.

[25] ASTM, "Standard specification for concrete aggregates," Tech. Rep. C33/C33 M, ASTM, West Conshohocken, Pa, USA, 2008.

[26] ASTM, Standard Specification for Aggregate for Masonry Mortar, C144, ASTM, West Conshohocken, Pa, USA, 2004.

[27] ABAQUS Inc, ABAQUS/CAE User's Manual, Version 6.10, 2006.

[28] H. Yaginuma, M. Tanaka, A. Kasahara, and S. Yazawa, "Development of a standard for block dimensions for use under Japanese conditions," in Proceedings of the 7th International Conference on Concrete Block Paving (CBP '03), Sun City, South Africa, October 2003.

[29] B. Shackel, "The performance of interlocking block pavements under accelerated trafficking," in Proceedings of the 1st International Conference on Concrete Block Paving (CBP '80), pp. 113120, Newcastle upon Tyne, UK, 1980.

[30] Korea Pavement Research Program Report, Korean Pavement Design Guide, Ministry of Land, Transport and Maritime Affairs, 2011.

[31] W. G. Lin, S. W. Ryu, and Y. H. Cho, "Performance of permeable block pavements in accelerated pavement test and rainfall simulation," Journal of Performance of Constructed Facilities, vol. 30, no. 1, 2016.

[32] Y. Hiroshi, I. Takashi, and I. Takuya, "Evaluation on durability of interlocking block pavement under repeated loading by heavy vehicles," in Proceedings of the 3rd International Workshop on Concrete Block Paving, pp. 10-13, Cartagena de Indias, Colombia, May 1998. 

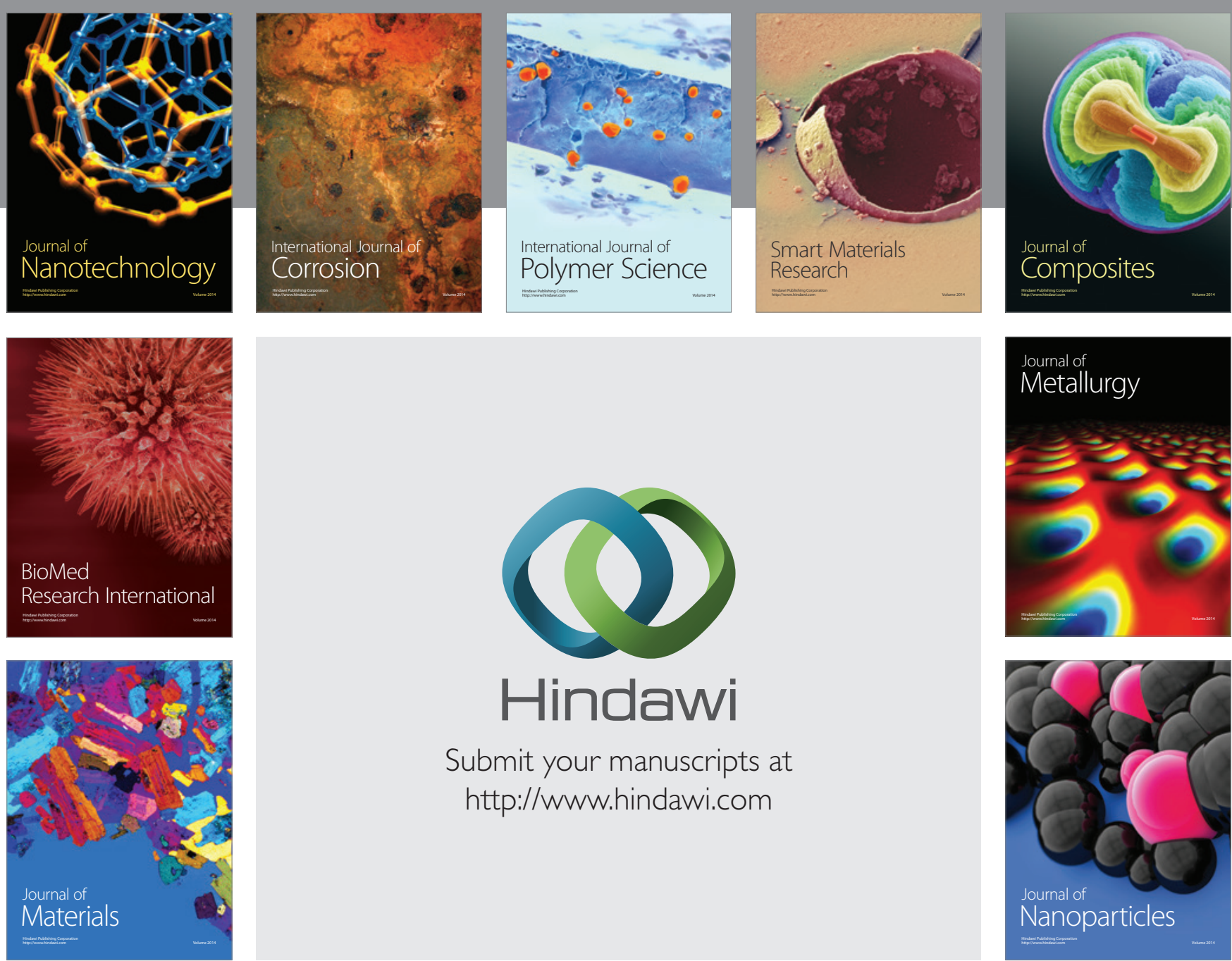

\section{Hindawi}

Submit your manuscripts at

http://www.hindawi.com

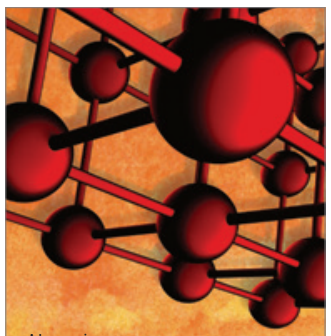

Materials Science and Engineering
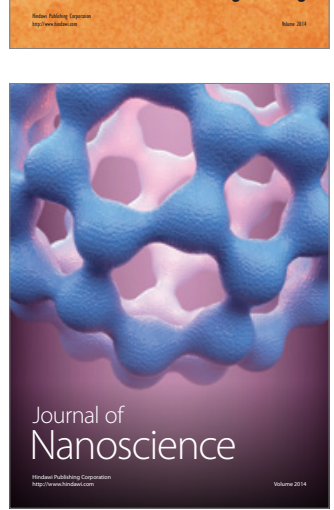
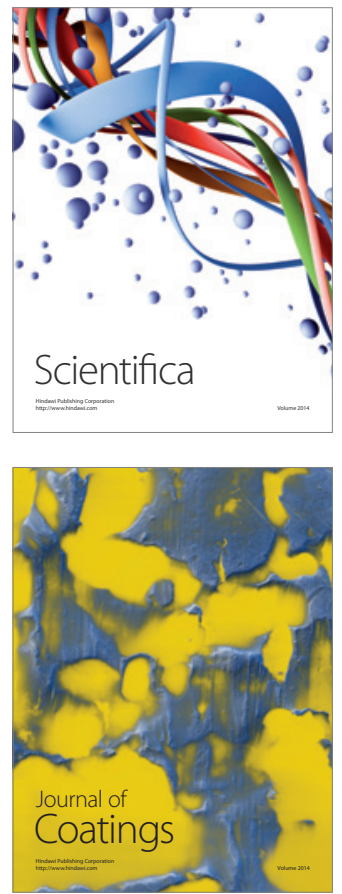
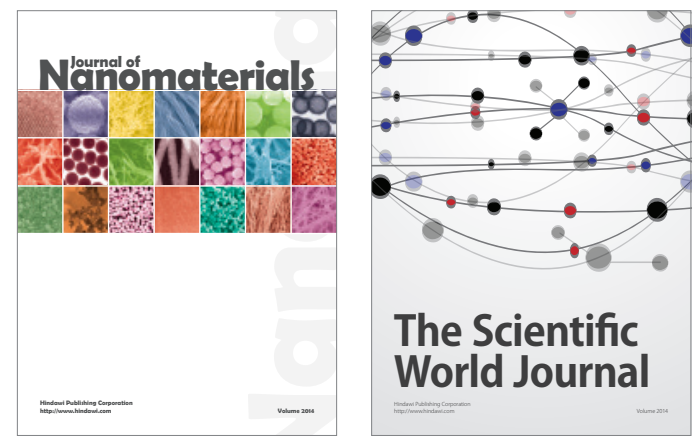

The Scientific World Journal
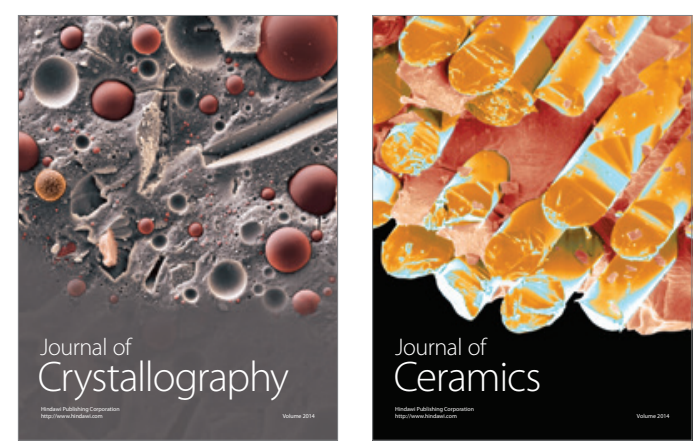
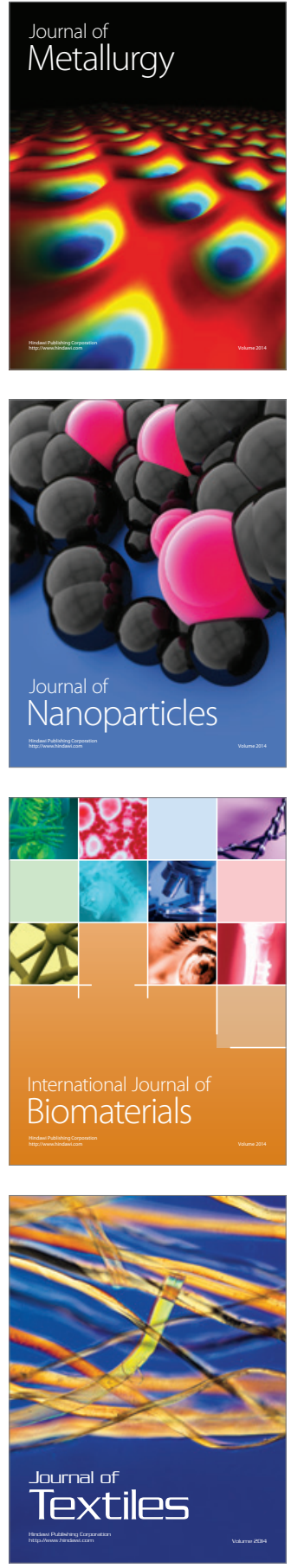